\title{
Review
}

Pharmacology

\section{Clonidine Use in Psychiatry: Panacea or Panache?}

\author{
Ahmed Naguy \\ Child and Adolescent Psychiatrist, KCMH, Shwaikh, Kuwait
}

\section{Key Words}

Clonidine $\cdot$ Psychiatric uses

\section{Abstract}

Clonidine, an alpha agonist, formally prescribed in clinical medicine as antihypertensive medication, is currently being used more frequently to address a multitude of psychiatric entities. The long-acting formulation is approved by the Food and Drug Administration for use in treating the attention-deficit/hyperactivity disorder. In addition to this only legitimate indication, it has long been used successfully for opiate detoxification, post-traumatic stress disorder and de la Tourette syndrome. Moreover, clonidine helps in the treatment of neuroleptic-induced akathisia, stimulant-induced insomnia and clozapine-induced sialorrhea. It has been tried in treating menopausal syndrome and psychogenic polydipsia. Although the strength of evidence supporting the use of clonidine in such clinical scenarios is highly variable and oscillating, from strong to only flimsy, this overview is intended to shed some light on the clonidine portfolio as a potential and attractive addition to the psychopharmacologic armamentarium.

(c) 2016 S. Karger AG, Basel

\section{Introduction}

Clonidine is a non-selective alpha-2 adrenergic agonist that has been used in psychiatric practice in panoply of clinical indications. According to recent trends, its utilization is on the increase. In this study, we are reviewing the pharmacology of clonidine followed by its use in such diverse indications and the extant evidence. Searching PubMed database was pursued using key words of 'clonidine' 'psychiatric uses'.

\section{Pharmacology of Clonidine}

Clonidine is an alpha-2 adrenergic agonist. It is nonselective in the sense that it binds to alpha-2A, B and C subtypes [1] (cf. guanfacine, which is more selective to alpha-2A). It acts presynaptically to reduce sympathetic outflow and hence, decreasing cardiac output, peripheral vascular resistance and blood pressure. It specifically targets alpha-2 receptors in the brainstem vasomotor centre, decreasing presynaptic Ca levels and release of NE. It may also reduce plasma renin activity and catecholamine ex-

\section{KARGER}

E-Mail karger@karger.com www.karger.com/pha
(C) 2016 S. Karger AG, Base

0031-7012/16/0982-0087\$39.50/0
Ahmed Naguy, MBBch, MSc

Al-Manara Centre for CAP

KCMH, Shwaikh (Kuwait)

E-Mail ahmednagy@ hotmail.co.uk 
cretion. It possesses imidazoline I1 agonistic activity that contributes to its antihypertensive action [2].

Clonidine comes in a variety of drug formulations, namely, oral tablets, transdermal patches and concentrates for injection as epidural infusion. Also, topical gel is increasingly being used in diabetic neuropathy. This would translate into clinically user-friendly administration [1].

Posology (dosage) differs according to indication and formulation employed but generally between 100 and 800 $\mu \mathrm{g} /$ day (divided) [1].

Half-life is $12 \mathrm{~h}$ in most. Peak effect is at $2-4 \mathrm{~h}$. Bioavailability is $75-95 \%$ with $1 / 2$ of drug metabolized into inactive metabolites and the other half excreted unchanged in urine [1].

Most common adverse drug reactions are dose-related, time-limited and mostly affect CNS (dizziness, somnolence, depression), CVS (orthostasis, bradycardia) and GIT (dry mouth, constipation). Rebound hypertension with abrupt discontinuation is a definite risk [1]. It is pregnancy category C. It has been used even in preschool children reflecting high safety and tolerability issues.

\section{Clonidine in ADHD}

Alpha-2 adrenergic receptors are present in high concentrations in the prefrontal cortex (PFC) but only in low concentrations in the nucleus accumbens. The most prevalent subtype in PFC is the alpha-2A apparently mediating inattentiveness, hyperactivity and impulsivity. Alpha- $2 \mathrm{~B}$ receptors are located mainly in thalamus associated with sedation. Alpha-2C is located in locus coeruleus associated with hypotensive and also sedative actions [3].

All these pharmacologic properties would explain the utility of clonidine in attention-deficit/hyperactivity disorder (ADHD). And hence, the long-acting formulation was approved by the Food and Drug Administration as monotherapy or adjunctive to stimulants in treatment of ADHD above the age of 6 [4].

Two randomized, double-blind, placebo-controlled, 8 weeks efficacy studies in paediatric patients aged 6-17, demonstrated significant improvement over placebo in ADHD rating scale total score at the end of week 5 [4].

A multi-centre, open-label, flexible-dose, chronic exposure evaluation of safety study including 301 cases in the age group 6-17, reported only one case of suicidal behaviour [4].

A meta-analysis of 11 small double-blind and openlabel studies (less than 50 subjects) reviewing the effect of immediate-release clonidine on symptoms of ADHD alone or with comorbidities determined a moderate overall effect size of $0.58 \pm 1.6$ [5].

A systematic review and meta-analysis of 12 placebocontrolled trials - 9 as monotherapy and 3 as augmentation - was recently conducted to evaluate safety and efficacy of alpha- 2 agonists (clonidine but also guanfacine) in paediatric ADHD and demonstrated superiority to placebo as monotherapy and to a lesser extent as a cotreatment. However, somnolence, bradycardia and hypotension were greater in the active arm [6].

This clearly obviates previous earlier concerns about cardiovascular fatalities reported with clonidine-stimulant combinations [7].

It seems that clonidine may work in a synergistic fashion with stimulants through the regulation of PFC [8].

This enhanced efficacy has been ensured without compromising safety [9].

Moreover, clonidine seems to be an attractive option targeting insomnia in ADHD [10] and remain a good remedy for paediatric insomnia in general [10], and a case series has also reported that clonidine seems to be beneficial and fairly well tolerated in intractable sleep disorders in children and young adults with neurodevelopmental disorders [11].

To extrapolate, clonidine has been tried in 8 kids with hyperkinetic autism spectrum disorder (ASD), with statistically and clinically relevant decrease in irritability subscale of aberrant behaviour checklist [12].

Clonidine was also effective in reducing sleep initiation latency and night awakening, to a lesser degree in improving ADHD symptoms, mood instability and aggressiveness in a cohort of 19 children with ASD [13].

A double-blind, placebo-controlled trial of clonidine in hyperactive children with mental retardation found it both safe and effective with drowsiness as a common side effect that typically wore off by $2-4$ weeks [14].

\section{Clonidine in Opiate Detoxification}

Clonidine has long been used successfully to rapidly suppress opiate withdrawal signs and symptoms [15] and a review on the topic suggested utility especially when methadone substitution is inappropriate.

It helps opiates detoxification by reducing sympathetic overactivity, for example, tachycardia, hypertension, sweating, flashes and restlessness [16].

Moreover, it eases accompanying insomnia.

Clonidine has also been used for enabling alcohol withdrawal [17], as its superiority to placebo was demonstrated in several double-blind studies. 
Clonidine was more effective than placebo for longterm smoking cessation [18] in a Cochrane database review of 6 trials with dry mouth and sedation reported as most troublesome side effects.

\section{Clonidine in PTSD}

A burgeoning body of evidence exists as regards the role of clonidine in post-traumatic stress disorder (PTSD).

This is achieved putatively through the reduction of CNS noradrenergic activity.

Clonidine was reported in an open-label case series to reduce PTSD trauma nightmares and improve sleep in Cambodian refugees and improve PTSD symptoms in veterans [19].

Improved sleep in one open-label study was accompanied by improved sleep physiology objectively demonstrated with polysomnography [20].

Clonidine has been shown to block traumatic memories in an animal model of PTSD [21, 22].

Clonidine has helped with nightmares in 2 case reports of PTSD comorbid with TBI [23].

Clonidine, as add-on, has been demonstrated in a randomized, double-blind, placebo-controlled cross-over study of 18 patients, to improve hyperarousal in borderline personality disorder (BPD) particularly with comorbid PTSD, although this did not achieve significance possibly due to small sample size [24].

Also, a study of 14 female patients with BPD showed efficacy of clonidine in acute states of aversive inner tension, dissociative symptoms, and urge to commit self-injurious behaviours [25].

Conceivably, due to sedative effects, clonidine would address sleep disturbance in PTSD.

\section{Clonidine in dTS}

Studies supporting utility of clonidine in ameliorating tics abound demonstrating efficacy of circa $45 \%$ with few, if any, side effects $[26,27]$. Antipsychotics were more efficacious in an open trial [28]. Some have found clonidine to be as efficacious as haloperidol [29] and another pilot study has demonstrated equal efficacy with risperidone in children with de la Tourette syndrome (dTS) [30].

In patients who have been shown to respond to clonidine, positive effects have been reported on a range of behavioural symptoms in addition to tics. These include compulsions [31], hyperactivity and impulsivity [27].
Some authors have demonstrated that $70 \%$ of patients showed a reduction in tics and that additional improvement in frustration, aggression, obsessive-compulsive and oppositional behaviours were noticed [32].

A small (including 12 subjects) double-blind crossover study compared clonidine and the anti-epileptic levetiracetam. Subjects were aged 8-27. There was a small but significant benefit from clonidine with an effect size of 0.57 [33].

As ADHD is the most common comorbid condition in dTS up to $60-80 \%$ [34], clonidine seems a reasonable option targeting both symptomatology without concern about using stimulants that are still considered a relative contraindication in dTS for unjustifiable fears of inducing or exacerbating tics.

In a meta-analysis to determine the relative efficacy of different medications in treating ADHD and tic symptoms in children with both Tourette's syndrome and ADHD, Alpha- 2 agonists demonstrated ESs of 0.76 and 0.75 in treating inattention and hyperactivity/impulsive symptoms of ADHD, whereas the ESs for methylphenidate were 0.41 and 0.82 , respectively. Alpha-2 agonists seem like a better choice of medication when targeting comorbid tic symptoms, and methylphenidate derivatives as a better choice when targeting tics is not a priority. A combination treatment of both agents may be most effective in targeting both disorders together [35].

Given the complexity of dTS exemplified by the heterogeneity of clinical presentation, numerous neurotransmitters have been proposed as potential pathophysiologic mechanisms including dopamine, glutamate, GABA, serotonin, acetylcholine, norepinephrine and opiates [36].

Although, this could explain in part the role of clonidine in treatment of dTS, the definite mechanism is far from clear.

Recent work pointed to sensorimotor gating abnormalities in dTS and that clonidine could normalize these deficits [37].

\section{Clonidine in Neuroleptic-Induced Akathisia}

Although, there are several effective lines of treatment tackling neuroleptic-induced akathisia (i.e. beta-blockers, BDZs, anticholinergics, 5HT2a antagonists), clonidine remains a potential option [38-40].

Six patients with akathisia were treated with clonidine in an open on-drug/off-drug trial, all demonstrated substantial improvement of which 4 achieved complete remission [38]. 
Table 1. Clonidine uses in psychiatry

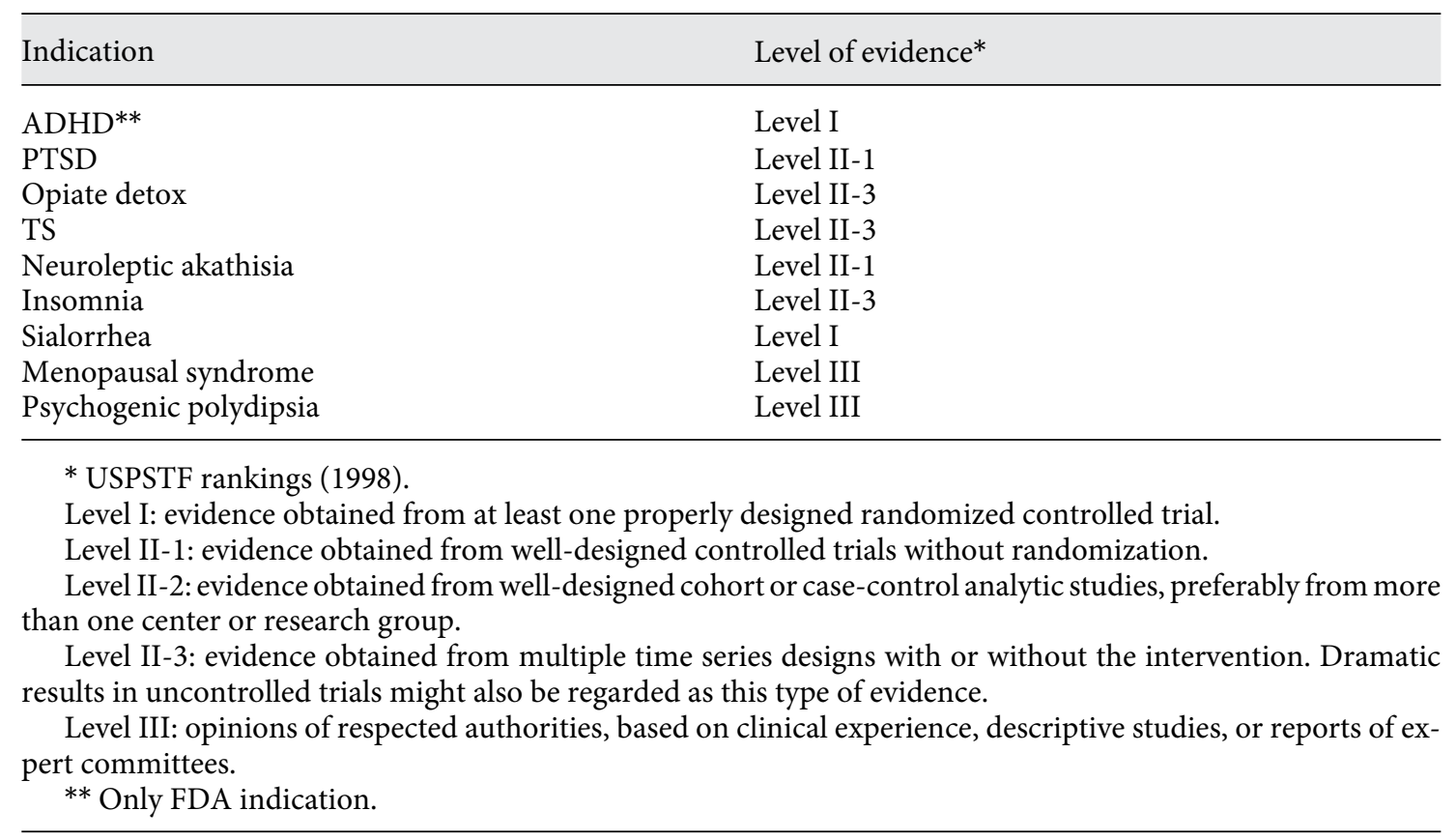

Another 6 hospitalized patients with neuroleptic-induced akathisia were treated with clonidine under singleblind conditions. Akathisia and anxiety at maximum clonidine dose were significantly lower than at baseline, although it was difficult to differentiate specific therapeutic effects from sedation [39].

\section{Clonidine in Clozapine-Sialorrhea}

Despite demonstrated superiority of clozapine in treatment-resistant schizophrenia, its use is usually plagued with a myriad of troublesome side effects, including sialorrhea.

One postulated mechanism of this sialorrhea is alpha-2 adrenolytic action.

This can in theory be opposed by clonidine and in practice has been shown to be useful [41, 42].

Oral clonidine was tried on 12 stable outpatients of schizophrenia maintained on clozapine. Wet area over the pillow as reported by the patients was recorded at baseline and at 4 weeks of treatment along with the subjective response after the treatment. Most of the patients reported a decrease in sialorrhea without any adverse events [41].

A $0.1 \mathrm{mg} /$ day once-a-week clonidine patch was administered to 4 patients with clozapine-induced hyper- salivation. The author reports a sustained improvement in 2 patients, a limited and short-lived improvement in another and no improvement in the fourth [42].

Similarly, clonidine has been used with success to address sialorrhea in Parkinson's disease [43] in a prospective double-blind placebo compared study following Parkinson's disease patients for 3 months.

\section{Clonidine in Psychogenic Polydipsia}

Psychogenic polydipsia is characterized by compulsive water drinking typically in excess of 3 liters, often in circa $6-20 \%$ of the mentally ill or developmentally disabled with cerebral oedema and potentially fatal outcome [44].

This is commonly seen in people with schizophrenia, developmental disability and middle-aged women with anxiety disorders [45].

Treatment options include managing hyponatremia, restriction of fluids and medications, for example, clozapine [46], demeclocycline [47], enalapril and clonidine [48].

Animal studies have suggested the involvement of adrenergic system in drinking behaviour [49] and this was demonstrated in a pilot study of 4 patients with chronic schizophrenia presenting with intermittent hyponatremia and polydipsia, where mianserin, unlike clonidine, was helpful. 
A pilot study included 3 patients with chronic schizophrenia and primary polydipsia questioned overall effectiveness of clonidine, which was unsuccessful [50].

\section{Clonidine in Menopausal Syndrome}

Vasomotor changes including hot flashes and night sweats occurred in up to $70 \%$ of women at the time of menopause with significant impact on quality of life [51].

Management included lifestyle modifications, some herbal and vitamin supplement, HRT, clonidine, SNRIs and gabapentin [52].

CNS sympathetic overactivity, mediated through alpha-2 adrenergic receptors, is an important factor responsible for the narrowing of the thermoneutral zone underlying hot flashes [52].

\section{Other Uses}

Clonidine has also been tried in a multitude of neuropsychiatric disorders [53].
This includes, inter alia, migraine, tardive dyskinesia [54], essential tremor [55], neurogenic bladder [56], idiopathic orthostatic hypotension, paroxysmal localized hyperhidrosis [57], diabetic neuropathy [58] and stiff-man syndrome [59].

\section{Conclusion}

This overview has cast some light on the clonidine portfolio as a pluripotent, reasonably safe and appealing contribution to the psychopharmacologic armamentarium. Nevertheless, the level of evidence supporting the use of clonidine in all these off-label indications is highly variable (table 1), and hence, sound clinical judgment, manipulating all other viable treatment options at hand, would dictate its judicious and proper use and placement in real-life psychiatric practice.

\section{Disclosure Statement}

Author declares no conflicts of interest or financial affiliations with pharmaceutical companies or industry-sponsored research.

\section{References}

1 Neil MJ: Clonidine: clinical pharmacology and therapeutic use in pain management. Curr Clin Pharmacol 2011;6:280-287.

2 Reis DJ, Piletz JE: The imidazoline receptor in control of blood pressure by clonidine and allied drugs. Am J Physiol 1997;273(5 pt 2): R1569-R1571.

3 Stahl SM: Stahl's Essential Psychopharmacology: Neuroscientific Basis and Practical Applications, ed 4, 2013.

4 FDA approval of Kapvay, 2010.

5 Connor DF, Fletcher KE, Swanson JM: A meta-analysis of clonidine for symptoms of attention-deficit hyperactivity disorder. J Am Acad Child Adolesc Psychiatry 1999;38:1551-1559.

6 Hirota T, Schwartz S, Correll CU: Alpha-2 agonists for attention-deficit/hyperactivity disorder in youth: a systematic review and meta-analysis of monotherapy and add-on trials to stimulant therapy. J Am Acad Child Adolesc Psychiatry 2014;53:153-173.

7 Maloney MJ, Schwam JS: Clonidine and sudden death. Pediatrics 1995;96:1176-1177.

8 Childress AC, Sallee FR: Revisiting clonidine: an innovative add-on option for attentiondeficit/hyperactivity disorder. Drugs Today (Barc) 2012;48:207-217.

9 Sallee FR, Connor DF, Newcorn JH: A review of the rationale and clinical utilization of al- pha-2 adrenoceptor agonists for the treatment of attention deficit/hyperactivity and related disorders. J Child Adolesc Psychopharmacol 2013;23:308-319.

10 Barrett JR, Tracy DK, Giaroli G: To sleep or not to sleep: a systematic review of the literature of pharmacological treatments of insomnia in children and adolescents with attention-deficit/hyperactivity disorder. J Child Adolesc Psychopharmacol 2013;23:640-647.

11 Heussler H, Chan P, et al: Pharmacological and non-pharmacological management of sleep disturbance in children: an Australian paediatric research network survey. Sleep Med 2013;14:189-194.

12 Jaselskis CA, Cook EH Jr, Fletcher KE, et al: Clonidine treatment of hyperactive and impulsive children with autistic disorder. J Clin Psychopharmacol 1992;12:322-327.

13 Ming X, Gordon E, Kang N, et al: Use of clonidine in children with autism spectrum disorders. Brain Dev 2008;30:454-460.

14 Agarwal V, Sitholey P, Kumar S, et al: Doubleblind, placebo-controlled trial of clonidine in hyperactive children with mental retardation. Ment Retard 2001;39:259-267.

15 Kleber HD, Gold MS, Riordan CE: The use of clonidine in detoxification from opiates. Bull Narc 1980;32:1-10.
16 Giannini AJ: Drugs of Abuse, ed 2.

17 Cushman P Jr: Clonidine and alcohol withdrawal. Adv Alcohol Subst Abuse 1987;7:1728.

18 Bentz CJ: Review: clonidine is more effective than placebo for long-term smoking cessation, but has side effects. ACP J Club 2005; 142:12.

19 Kinzie JD, Leung P: Clonidine in Cambodian patients with posttraumatic stress disorder. J Nerv Ment Dis 1989;177:546-550.

20 Kinzie JD, Sack RL, Riley CM: The polysomnographic effects of clonidine on sleep disorders in posttraumatic stress disorder: a pilot study with Cambodian patients. J Nerv Ment Dis 1994;182:585-587.

21 Zoladz PR, Fleshner M, Diamond DM: Differential effectiveness of tianeptine, clonidine and amitriptyline in blocking traumatic memory expression, anxiety and hypertension in an animal model of PTSD. Prog Neuropsychopharmacol Biol Psychiatry 2013;44: 1-16.

22 Gamache K, Pitman RK, et al: Preclinical evaluation of reconsolidation blockade by clonidine as a potential novel treatment for posttraumatic stress disorder. Neuropsychopharmacology 2012;37:27892796. 
23 Alao A, Selvarajah J, Razi S: The use of clonidine in the treatment of nightmares among patients with co-morbid PTSD and traumatic brain injury. Int J Psychiatry Med 2012;44: 165-169.

24 Ziegenhorn AA, Roepke S, et al: Clonidine improves hyperarousal in borderline personality disorder with or without comorbid posttraumatic stress disorder: a randomized, double-blind, placebo-controlled trial. J Clin Psychopharmacol 2009;29:170-173.

25 Philipsen A, Richter H, Schmahl C, et al: Clonidine in acute aversive inner tension and self-injurious behavior in female patients with borderline personality disorder. J Clin Psychiatry 2004;65:1414-1419.

26 Singer HS, Gammon K, Quaskey S: Haloperidol, fluphenazine and clonidine in Tourette syndrome: controversies in treatment. Pediatr Neurosci 1985-1986;12:71-74.

27 Leckman JF, Hardin MT, et al: Clonidine treatment of Gilles de la Tourette's syndrome. Arch Gen Psychiatry 1991;48:324-328.

28 Shapiro AK, Shapiro E, Eisenkraft GJ: Treatment of Gilles de la Tourette's syndrome with clonidine and neuroleptics. Arch Gen Psychiatry 1983;40:1235-1240.

29 Borison RL, Ang L, Hamilton WJ, et al: Treatment approaches in Gilles de la Tourette syndrome. Brain Res Bull 1983;11:205-208.

30 Gaffney GR, Perry PJ, Lund BC, et al: Risperidone versus clonidine in the treatment of children and adolescents with Tourette's syndrome. J Am Acad Child Adolesc Psychiatry 2002;41:330-336.

31 Leckman JF, Cohen DJ, Detlor J, et al: Clonidine in the treatment of Tourette syndrome: a review of data. Adv Neurol 1982;35:391-401.

32 Cohen DJ, Detlor J, Shaywitz BA, et al: Interaction of biological and psychological factors in the natural history of Tourette syndrome: a paradigm for childhood neuropsychiatric disorders. Adv Neurol 1982;35:31-40.

33 Rizzo R, Gulisano M: Clinical pharmacology of comorbid attention deficit hyperactivity disorder in Tourette syndrome. Int Rev Neurobiol 2013;112:415-444

34 Hedderick EF, Morris CM, Singer HS: Double-blind, crossover study of clonidine and le- vetiracetam in Tourette syndrome. Pediatr Neurol 2009;40:420-425.

35 Bloch MH, Panza KE, Landeros-Weisenberger A, et al: Meta-analysis: treatment of attention-deficit/hyperactivity disorder in children with comorbid tic disorders. J Am Acad Child Adolesc Psychiatry 2009;48:884-893.

36 Singer HS, Minzer K: Neurobiology of Tourette's syndrome: concepts of neuroanatomic localization and neurochemical abnormalities. Brain Dev 2003;25(suppl 1):S70-S84.

37 Eapen V, Ward P, Clarke R: Clonidine in Tourette syndrome and sensorimotor gating. Psychiatry Res 2014;215:494-506.

38 Zubenko GS, Cohen BM, Lipinski JF Jr, et al: Use of clonidine in treating neuroleptic-induced akathisia. Psychiatry Res 1984;13:253259.

39 Adler LA, Angrist B, Peselow E, et al: Clonidine in neuroleptic-induced akathisia. Am J Psychiatry 1987;144:235-236.

40 Poyurovsky M, Weizman A: Serotonin-based pharmacotherapy for acute neuroleptic-induced akathisia: a new approach to an old problem. Br J Psychiatry 2001;179:4-8.

41 Praharaj SK, Verma P, Roy D, et al: Is clonidine useful for treatment of clozapine-induced sialorrhea? J Psychopharmacol 2005; 19:426-428.

42 Grabowski J: Clonidine treatment of clozapine-induced hypersalivation. J Clin Psychopharmacol 1992;12:69-70.

43 Serrano-Dueñas M: [Treatment of sialorrhea in Parkinson's disease patients with clonidine. Double-blind, comparative study with placebo]. Neurologia 2003;18:2-6.

44 Verghese C, de Leon J, Josiassen RC: Problems and progress in the diagnosis and treatment of polydipsia and hyponatremia. Schizophr Bull 1996;22:455-464.

45 de Leon J: Polydipsia - a study in a long-term psychiatric unit. Eur Arch Psychiatry Clin Neurosci 2003;253:37-39.

46 Lee HS, Kwon KY, Alphs LD, et al: Effect of clozapine on psychogenic polydipsia in chronic schizophrenia. J Clin Psychopharmacol 1991;11:222-223.

47 Sanga M, Kurotani M, Nomura S: [Effects of demeclocycline on psychiatric polydipsia in schizophrenic patients]. Nihon Shinkei Seishin Yakurigaku Zasshi 1999;19:21-26.

48 Greendyke RM, Bernhardt AJ, Tasbas HE, et al: Polydipsia in chronic psychiatric patients: therapeutic trials of clonidine and enalapril. Neuropsychopharmacology $\quad 1998 ; 18: 272-$ 281.

49 Hayashi T, Nishikawa T, Koga I, et al: Involvement of the alpha2-adrenergic system in polydipsia in schizophrenic patients: a pilot study. Psychopharmacology (Berl) 1997;130: 382-386.

50 Delva NJ, Chang A, Hawken ER, et al: Effects of clonidine in schizophrenic patients with primary polydipsia: three single case studies. Prog Neuropsychopharmacol Biol Psychiatry 2002;26:387-392.

51 Umland EM, Falconieri L: Treatment options for vasomotor symptoms in menopause: focus on desvenlafaxine. Int $J$ Womens Health 2012;4:305-319.

52 Freedman RR: Menopausal hot flashes: mechanisms, endocrinology, treatment. J Steroid Biochem Mol Biol 2014;142:115-120.

53 Sandyk R, Gillman MA, Iacono RP, et al: Clonidine in neuropsychiatric disorders: a review. Int J Neurosci 1987;35:205-215.

54 Howland RH: Drug therapies for tardive dyskinesia: part 2. J Psychosoc Nurs Ment Health Serv 2011;49:17-20.

55 Serrano-Dueñas M: [Clonidine versus propranolol in the treatment of essential tremor. A double-blind trial with a one-year followup]. Neurologia 2003;18:248-254.

56 Rao MS, Bapna BC, Vaidyanathan S, et al: Use of clonidine in the management of patients with neurogenic bladder dysfunction. Eur Urol 1980;6:261-264.

57 Walling HW: Systemic therapy for primary hyperhidrosis: a retrospective study of 59 patients treated with glycopyrrolate or clonidine. J Am Acad Dermatol 2012;66: 387-392.

58 Campbell CM, Kipnes MS, Stouch BC, et al: Randomized control trial of topical clonidine for treatment of painful diabetic neuropathy. Pain 2012;153:1815-1823.

59 Shindo M: [Stiff-man syndrome]. Nihon Rinsho 1993;51:3024-3028. 